\title{
Estorbos a un regidor advenedizo: justicia, facciones y conflicto urbano en la España del siglo XVII
}

4 Tomás A. Mantecón Movellán

Universidad de Cantabria, España

Fecha de recepción: 4 de febrero de 2020. Fecha de aceptación: 19 de mayo de 2020.

\section{Resumen ${ }^{1}$}

Este artículo analiza la documentación que produjo la causa criminal contra un edil de la localidad granadina de Motril en la primera mitad del siglo XVII. El regidor Pérez Merino llegó a la villa en un contexto de recepción de inmigrantes en una comunidad urbana afectada de forma importante por la expulsión de los moriscos. Pérez, en ese contexto, se construyó un espacio de poder dentro del gobierno local. La fricción dentro de la élite gobernante acabó por generar una demanda criminal y un costoso expediente judicial que se resolvió finalmente por medio de la gracia del rey. El análisis de esta documentación permite explicar los rasgos del arquetipo de mal gobernante urbano; además, sopesar las distancias entre los discursos y las pruebas sobre los hechos y, finalmente, identificar las implicaciones, instrumentos y prácticas de la justicia para reconstruir la paz pública en la España del siglo XVII.

Palabras clave: Mal gobierno, justicia, España, siglo XVII, gracia del rey.

1 Esta investigación se integra en el proyecto Gobernanza, conflicto y construcción de cultura política (Ref. PGC2018-093841-B-C32) del Ministerio de Ciencia y Tecnología del Gobierno de España y en el marco del proyecto RESISTANCE-778076-H2020-MSCARISE-2017. 


\title{
Impediments for an upstart alderman: justice, factions and urban conflict in Spain's XVIIth Century
}

\begin{abstract}
This article analyses judicial documents produced to act against a local alderman of the small town of Motril in Southern Spain province of Granada in the first half of the 17th century, when this town -thanks to immigration- recovered the levels of population it had had before the expulsion of the Moors (moriscos). Isidro Pérez Merino, the aldermen prosecuted, arrived to Motril in this historical context and he had empowered his social position in the urban community and government before being accused for several charges, including some homicides. This produced a judicial battle with his rivals in Motril. This casewas solved by the royal grace in the end. The analysis of these documents allows us to explain, first, the archetype of bad urban governor; second, the distances between judicial discourses and proofs and, lastly, justice instruments and practices to rebuilt public peace in 17 th century Spain.
\end{abstract}

Keywords: Bad government, justice, Spain, 17th century, royal grace.

Esta investigación parte del análisis de un sustancial fragmento biográfico de un regidor de la ciudad andaluza de Motril, en la costa de Granada en la primera mitad del siglo XVII. Isidro Pérez Merino, a pesar de edil municipal, tal como lo describieron las informaciones contenidas en el proceso formado contra él en la chancillería de Granada, era todo lo contrario a la imagen de un buen vecino en su entorno urbano de la España meridional de este periodo histórico. Entre sus múltiples excesos, este hombre acumulaba varias víctimas de homicidios cometidos, al parecer, debido a su mal ejercicio de la profesión médica para la que él se consideraba perito. Eso, al parecer, había provocado su emigración forzosa de distintos lugares de residencia en Andalucía, tratando de evitar posibles problemas con vecinos y quizá con la justicia ya en las primeras décadas del siglo XVII. Cuando fue juzgado y condenado por la justicia, en 1635, ya había protagonizado una larga peregrinación motivada, aparentemente, por este tipo de situaciones complicadas de ser evaluadas judicialmente.

Estudiar este conflicto hasta donde habilitan las fuentes consultadas permite reconstruir los límites de la tolerancia urbana hacia comportamientos excesivos que eran protagonizados por sus gobernantes en la España del siglo XVII, puesto que se señalan líneas de intransigencia o conflicto en este 
caso que fueron superadas y que, por esa razón, generaron una demanda judicial contra un regidor en 1635. El análisis casuístico también ofrece información sobre las fronteras entre la integración y exclusión social en las sociedades urbanas del Antiguo Régimen, ya que los argumentos esgrimidos en la demanda debieron ser verificados judicialmente y, sin embargo, no lo fueron en todos sus extremos, lo que permite sopesar la articulación de una opinión adversa al regidor forastero en Motril.

La crítica contra Isidro Pérez Merino era articulada por rivales en el ejercicio del poder en un municipio que debió compensar las pérdidas de efectivos demográficos después de la expulsión de los moriscos. Recibió entonces inmigrantes del interior de la región. De alguna manera, el conflicto que denotaban las acusaciones contra Pérez Merino también se alimentaba de la tensión política en la gestión del gobierno urbano relacionada con esta atmósfera de cambio previo al reconocimiento regio de la condición de ciudad para esta localidad andaluza en 1657.

El estudio de la restauración de la paz pública y la superación del conflicto es una preocupación clásica del pensamiento jurídico desde los fundamentos en la escolástica hasta las reflexiones de nuestro tiempo, y no se trata, por lo tanto, de una materia fácil de analizar, puesto que lo que encuentra el científico al bucear en las fuentes son realidades sociales muy diversas, dinámicas y con sistemas de referencia jurídica que hacen difícilmente comparables las nociones de justicia o de injusticia en diferentes sociedades, contextos y momentos.

Un argumento tan aparentemente simple como el aserto aristotélico de que la injusticia aflora cuando los iguales son tratados con desigualdad o los desiguales con igualdad ya enunciaba la enorme complejidad del problema, la equidad era exigible en un juicio justo. ${ }^{2}$ A estas dificultades de análisis hay que añadir la imprescindible necesidad de extremar las sensibilidades del analista hacia los contextos, para entender los referentes del momento y explicar los conflictos y las resoluciones de los mismos. El esquema se complica más debido a que el cambio histórico también otorgaba cierto dinamismo tanto a las definiciones como a los contextos.

Con el propósito de atender a estas consideraciones se plantear aquí el estudio justamente concentrado en el análisis del conflicto, los discursos sobre el mismo y las formas de recomposición del orden en un entorno urbano como el estudiado en la España del siglo XVII, atendiendo a los

2 Morris Ginsberg (1965) ya trató de enfrentarse a esta materia en una sintética y clarificadora obra de madurez. 
espacios que ofrecía la concepción de la justicia y los usos sociales de la misma en esos contextos históricos. El estudio de esta materia, por su parte, ha cobrado un renovado interés desde las dos últimas décadas del siglo XX y conecta con una relevante preocupación en las sociedades de nuestro tiempo.

\section{Conflictos, arbitrajes y gobernanza}

Conocer las formas en que los entornos sociales participaron históricamente y lo hacen hoy en acciones y procesos de resolución de conflictos y construcción de una convivencia ciudadana es una inquietud tanto social como científica. Los ejemplos de esa inquietud son numerosos e insisten en el peso relevante de la negociación entre partes, mediaciones y arbitraje en el proceso de resolución de conflictos, tanto en lo que se refiere a las épocas de la Edad Moderna temprana (Powell, 1984: 21-43; Mantecón, 2002: 43-76) como en el momento presente, a la hora de enfrentarse al problema de lograr mejores escenarios para superar los conflictos sociales (Kurki, 2000: 235-303).

Esta investigación analiza los elementos de recomposición de la paz y el orden fruto de la acción de la justicia en cada uno de sus ámbitos, así como los que intervenían en las tensiones entre las partes en litigio y sus entornos sociales respectivos dentro de un escenario urbano, sin desatender a la intervención de la justicia y la gracia ejercida por el monarca.

Al mismo tiempo, esta investigación, que evalúa los grados de certidumbre e imaginación empleada en la construcción de los discursos judiciales, implica no perder el objetivo de un enfoque comparativo para subrayar las analogías y divergencias en el modo en que las ciudades occidentales de la temprana Edad Moderna reaccionaban ante excesos que suponían una ruptura de la paz pública y ponían a prueba la permisividad institucional y social, permitiendo conocer fronteras de la tolerancia hacia los comportamientos que las gentes consideraban tan extremados e intolerables como para generar exclusión social. Por este medio, se expresaban valores que articulaban una ética construida fruto de la convivencia cotidiana, así como sus límites.

Los arbitrajes ya formaban parte de las tradiciones urbanas de la Europa bajomedieval. Permitían equilibrar las tensiones desencadenadas en su seno y con otras comunidades y afectaban tanto a materias de gobierno interior como a la gestión de recursos, derechos y usos y, por supuesto 
a la convivencia social dentro de la urbe. Numerosos estudios abordan esta problemática y permiten obtener una buena imagen del conjunto, incluyendo también la superposición de una autoridad arbitral superior dentro de estructuras monárquicas (Attreed, 1992: 205-235; Powell, 1984: 21-43; Nader, 1990; Fortea, 2004: 235-278; Truchuelo, 2013; Breen, 2011: 346-386).

Los vecindarios, articulados de muy diversas formas, dispensaron a las gentes del Antiguo Régimen variadas opciones de mediación y arbitraje informales, desde el cotilleo hasta la murmuración e incluso la explosión de protestas colectivas. También dispensaron otras herramientas semiformalizadas para estos mismos fines, a través de instituciones sociales corporativas articuladas en barrios, cofradías o concejos. Obvia e igualmente, las gentes podían acudir a los procedimientos formalizados y sujetos a protocolos específicos definidos por la ley o por la costumbre. En todos estos supuestos, de los que se tienen noticias bastante precisas en nuestros días, el protagonismo estaba en la comunidad, que se expresaba de muy distintas maneras.

Pueden encontrarse testimonios de este tipo de mediaciones y arbitrajes en una abundante bibliografía que ha atendido a las concreciones globales del fenómeno (Roodenburg \& Spierenburg, 2004 y Matikainen \& Lidman, 2014 entre otros), al tiempo que en enfoques monográficos, concentrados en el papel jugado por las cofradías religiosas (Mantecón, 1990: 83-122 y 175-186), o las variadas reacciones vecinales frente a la violencia marital (Hufton, 1997: 284-293 y Mantecón, 1998). La labor realizada por mediadores semiformales como los párrocos o bien los sujetos considerados "hombres buenos" en el propio entorno social, también es conocida tanto para el caso hispano como europeo ya desde la baja época medieval incluso, como en el americano en los siglos de la Edad Moderna (Sabean, 1993: 144-173; Mantecón, 1995: 149-156 y Barral, 2008: 151-174).

En estas páginas se analiza, no obstante, una de las facetas de esos problemas urbanos, las prácticas de recomposición de los conflictos suscitados entre un individuo y otros, así como con las sociedades de su entorno y el impacto de todo ello en el ámbito institucional en diferentes planos, desde la justicia local hasta el ámbito de la gracia del rey, expresión suprema de potestas regia en esa "comunidad grande compuesta de muchas ciudades" que eran la Corona de Castilla y la Monarquía Hispánica. ${ }^{3}$

3 Sobre la noción de potestas y su relación con la auctoritas regia con una perspectiva comparativa en el pensamiento europeo tempranomoderno ver Tuck (1974: 43-61). La referencia textual, que alude a la estructura global como una communitas communitatis 
Si la imagen y alegoría de Juan Palafox y Mendoza sobre la Monarquía y sus problemas de conservación es realista cuando se planteaba “¿qué será una ciudad llena de hombres? ¿qué una provincia que está llena de ciudades? ¿qué una corona llena de muchas provincias? ¿qué una monarquía llena de muchas coronas?” (Gil Pujol, 2016: 21), ${ }^{4}$ cada ámbito de convivencia social de todos estos mencionados implicaba sus propios escenarios y vigores y, así, son múltiples los planos que deben ser analizados para conocer la cristalización del conflicto, las percepciones del mismo, las acciones sociales e institucionales dispuestas para superarlo y su resolución.

Algunas aportaciones de la tratadística tempranomoderna europea, conscientes de la misma realidad que dibujaba Palafox con esa alegoría de la Monarquía, consideraban la multiplicidad de ésta como una consecuencia directa del pecado original, es decir, una especie de condena con la que tenía que enfrentarse el género humano. Incluso se llegaba a tener a Caín por fundador de la primera ciudad y, así, por lo tanto, como responsable que "efectuó la división de términos". 5

De algún modo, el conflicto, que podía producirse en cada escenario de convivencia, debía recomponerse también en cada uno de esos términos y espacios, desde el ámbito de la experiencia individual y la esfera local hasta el campo de acción del monarca. El ejemplo que se analiza en estas páginas permite un análisis de esta problemática.

\section{Excesos del regidor advenedizo}

El 29 de julio de 1635, cuando se recibieron en la Cámara de Castilla los autos criminales contra Isidro Pérez Merino, médico, vecino y regidor en la villa de Motril, según su abogado, este hombre llevaba más de diez años ejerciendo como regidor y nueve de ellos también como médico. Este trámite llegaba a Madrid en respuesta a la diligencia dada en la capital el 16 de julio de 1635 y dirigida a la Chancillería de Granada con el fin de recabar

procedente de una consulta sobre Cortes castellanas de 1662 (Fernández Albaladejo, 1992: 331-332; también mencionado por Gil Pujol, 2016: 21).

4 La referencia de Palafox citada por Gil Pujol es procedente de su Historia real y sagrada, luz de príncipes y súbditos, de 1643.

5 Así lo explicó, por ejemplo, Suárez en su De legibus, pero estas percepciones tenían un anclaje profundo en los inicios del siglo XVI, cimentado sobre los procesos de construcción de las estructuras políticas monárquicas apoyadas también sobre proyectos dinásticos (Gil Pujol, 2016: 30-33). 
el expediente concerniente a este supuesto delincuente y resolver el suplicatorio que él mismo había elevado a la Cámara, para tratar de lograr una acción de gracia regia que atenuara la culpa criminal que se le achacaba por diversos y acumulados excesos penales en el tribunal granadino, y que le había dispensado ya una sentencia condenatoria.

El documento utilizado como fuente de información para conocer los comportamientos de este criminal, su significación contextualizada y las reacciones de los entornos sociales en que desarrolló su vida es un traslado autorizado remitido a la Cámara de Castilla de los autos, información y sentencia dada contra Isidro Pérez, demandado por el licenciado Luis de Ojeda, ante los alcaldes del crimen de la Chancillería de Granada.

El regidor logró el indulto que suplicaba. Así se dispuso por decisión del 20 de agosto de 1635. No obstante, se estableció una compensación de 1.00o reales que debía de pagar el reo, de los cuáles 200 debían aplicarse a reparar daños provocados a Doña Catalina del Campo, 100 para una muchacha llamada Marieta, ambas damnificadas por los malos tratamientos médicos dispuestos por el edil. El resto se quedaba en indemnizaciones para la Cámara de Castilla por gastos de justicia, y en manos de los oficiales que tramitaron el expediente por su intervención en el mismo. Las condiciones impuestas al reo para que el indulto regio fuera eficaz reconocían, como no podía ser de otro modo, la culpa o responsabilidad criminal del reo, requisito sin el que el perdón carecería de sentido. La gracia del rey se expresaba en esta última decisión, que se superponía a la previa del perdón privado otorgado por quienes representaban en el conflicto a la parte de las víctimas del criminal, beneficiarias, a su vez, finalmente, de estas tasadas compensaciones.

El licenciado Ojeda se había querellado tiempo atrás contra Isidro Pérez Merino y contra Cristóbal de Mirez, ambos vecinos de Motril. Ojeda indicaba que, en contra de las leyes vigentes que prohibían "que nadie pudiera curar en los reinos sin los requisitos de derecho, estando examinados por los protomédicos y teniendo licencia suya, ni yntitularse dotor si no es teniendo trato de universidad y traer mula con gualdrapa todo el año, el susodicho, contraviniendo a las dichas leyes, sin recados ningunos jurídicos”, se empeñaba en practicar medicina curativa allí, así como en otros lugares, intitulándose doctor, sin serlo.

El resultado de ese supuesto fraude fue que Isidro Pérez había practicado malas curas a muchos enfermos y que algunos de esos pacientes habían fallecido, ya fuera porque el tratamiento aplicado por Pérez Merino había sido agresivo contra la salud del enfermo o por la ineficacia del 
remedio dispuesto por el considerado médico para lograr la curación. "Especialmente, [se decía que] mató a una esclava de un rejidor de la dicha villa de Motril”, que era propiedad de Alonso Adriano Fernández Benegas.

Del homicida se decía, además, que era “ombre desonesto y que quando entra a curar las enfermas las solizita de amores, estando fuera de sus casas sus maridos, por lo qual le an suçedido muchos enfados y le an querido matar" 6 . En este punto, el de sus fragilidades sexuales, los relatos del demandante eran incluso más precisos sobre los excesos atribuidos a Isidro Pérez. El licenciado Ojeda indicaba que su acusado "con poco temor de Dios" estaba amancebado con una prima hermana suya a la que tenía dentro de su casa, que ella, había "estado presa en la [casa] de recoxidas," y que esta situación era escandalosa, "de tal suerte que estando acostado con su mujer, [él] se levanta de la cama y se va y acuesta en la de su prima”.

Incluso este mismo testigo indicaba que "abiendo sido [Isidro Pérez Merino un hombre] casado de primero matrimonio en la villa de Purchena”, en el río de Almanzora, "se vino a reprenderle ella [su esposa] el amancebamiento," y que, por esa causa, "mataron a dicha su mujer”, razón por la que "se le hizo causa y fue condenado a muerte y de horca; y[, sin embargo,] respeto de ser honbre poderosso [...], por malos medios, lo a impedido y se a quedado sin castigo un tan graue delito". El relato de los cargos contra el regidor de Motril ofrecía la imagen de este hombre como alguien capaz de todo tipo de comportamiento excesivo. Así, supuestamente, su itinerario vital le había hecho cambiar de residencia, empujado por una estela de tropelías supuestamente realizadas con una gran frialdad, y fruto de su necesidad de dar satisfacción a sus caprichos y debilidades sexuales personales.

Según parece, tiempo atrás, encontrándose en la villa de Cazorla, Pérez Merino ya había atendido y curado allí la enfermedad de un hombre llamado Bartolomé Martínez. Posteriormente, encaprichado con la esposa de éste, "por casarse con ella, en una granada, le dio beneno y mató a Bartolomé Martínez”. Esta muerte causó una gran conmoción en el vecindario, razón por la que él se asiló en un convento franciscano local, del cual lo había ayudado a salir un hermano suyo, fraile de San Francisco, que "lo sacó en ábito de fraile del dicho convento; y a andado sienpre ausente" del lugar desde entonces. 
Isidro Pérez Merino "es onbre ynquieto y revoltoso yncorrexible, perturbador de la republica y paz común” concluía Ojébar, querellante y vecino de Motril, cuando acudió a la justicia de la chancillería de Granada para denunciar a este hombre que había descrito, ya para entonces, un periplo por tierras andaluzas dejando a su paso lo que algunos de sus vecinos en Motril reconocían como una estela de excesos, tropelías y delitos fruto de sus caprichos. De este modo, "en la dicha ciudad de Baça salió huyendo de la de Loxa, de la de Cazorla, de la villa de Purchena y de las ciudades de Almería, Baeza y Xaén y que después que entró en la villa de Motril la tiene revuelta en bandos y todos estos pleitos se los an disimulado por ser rexidor y honbre poderoso, favorecido de las justiçias". ${ }^{7}$

Ya ubicado en Motril, donde se encontraba en el momento del proceso penal contra él, como regidor y dedicado a la práctica de la medicina, utilizaba los resortes de sus oficios y la influencia que era capaz de desplegar para afianzar un bloque de poder local, una facción, que le permitía irse empoderando dentro de la estructura local de relaciones sociales y políticas. Incluso trató de ubicar también como boticario de la villa a un pariente suyo llamado Cristóbal Mirez, casado con una prima hermana del regidor. De Mirez se decía que era también un "honbre imperito, y que en su vida a entendido [nada] de botica”.

Este asunto también había llegado por demanda a los juzgados de Granada. Allí, el regidor Pérez Merino logró testigos que declararon ser boticarios y vivir en la propia ciudad andaluza, pero, a juicido del demandante en la casusa contra él, lo hizo "siendo ansí que no biben en donde dizen ni ay tales honores”. Sin embargo, con esos testimonios Pérez Merino logró que la justicia amparara entonces sus posiciones e intereses. Así, su pariente estaba ya ubicado, asentando una botica en Motril, en el momento en que se conocían autos criminales contra el regidor en la chancillería de Granada. El proceso contra Pérez Merino iba dispuesto a dificultar este empoderamiento del edil advenedizo en Motril.

A principios de mayo de 1635, con todas esas informaciones se abrió un caso de corte en la Chancillería de Granada para analizar la veracidad de los cargos que se hacían contra el regidor Isidro Pérez Merino. La información practicada por el tribunal ofrece una encuesta de testimonios de personas que habían estado en los entornos vitales de este regidor alóctono en Motril, y que fueron recogidos esa primavera en el expediente judicial. 
Las declaraciones de los testigos presentados por las partes intervinientes en la causa permiten reconstruir la atmósfera social en que se desarrollaba la vida de Pérez Merino. Entre los presentados por el demandante, licenciado Ojeda, el 8 de mayo, destacaba la presencia trabajadores dependientes, con economías familiares muy fragilizadas, y también inmigrantes, forasteros o extranjeros en la villa de Motril. La traza y perfiles de estos testigos a priori tampoco parecía ofrecer la mayor fiabilidad sobre los contenidos de sus declaraciones.

\section{Las percepciones del entorno social}

Retornando al caso que ocupa en estas páginas, los testigos de la acusación fueron reconstruyendo entre todos el argumentario con que se abría la propia demanda contra el regidor Pérez Merino. El portugués Juan de Cuaresma, vecino de Granada aunque de nación portuguesa, que vivía y trabajaba empleado en la casa de un acomodado vecino de Granada llamado Pedro Adriano Benegas, declaró que conocía al acusado desde cuatro o cinco meses antes y sabía que era regidor en la villa de Motril; y que, como tal, le había visto en la villa, vigilando las tiendas, haciendo posturas con el alcalde mayor y practicando la medicina, curando enfermos tanto en Motril como otras partes, sin estar, según creía, examinado, ni tener licencia. Además, declaró que todo esto era muy bien conocido en el vecindario, por ser de dominio público.

Del mismo modo, el portugués declaró conocer que "por no saber curar el dicho Isidro Pérez Merino a ocasionado muchas muertes, por los malos medicamentos que aplica a los dichos enfermos”, como había ocurrido con una esclava de don Alonso Fernández Benegas, "a la que mató en seis días de tratamiento, y [añadía que] él [mismo] vio cómo le era reprendido [todos estos comportamientos] por un vecino, públicamente, al regidor Isidro". 8 En su declaración, también confirmó tener conocimiento del amancebamiento del regidor de Motril con una prima hermana suya, y añadió detalles sobre el carácter áspero, alborotador y pendenciero de este hombre que, según expresaban estos testimonios, traía en jaque a los demás vecinos de su villa.

Otros testigos de acusación, todos ellos integrados en las clases populares de lugares y entornos en que había desarrollado su vida el regidor de Motril, fueron añadiendo matices a cuanto se había descrito por el portugués. 
Juan Rodríguez, un "trabajador del campo" de Motril, por ejemplo, dijo que el regidor, a quien se refería como "el doctor Isidro", que llevaba sólo dos años en la villa, había provocado la muerte del regidor Benegas porque no le había practicado una sangría, "que era el remedio conveniente a su enfermedad según dixeron los médicos". ${ }^{9}$ Añadía este testigo, en su declaración, que no le resultaba tan raro el suceso, teniendo en cuenta que el acusado no había enseñado nunca los títulos que le asistían y eran legales para ejercer la medicina, y eso a pesar de que se los habían pedido en reiteradas veces.

También se confirmó que tenía en su casa a su prima hermana y que juntos habían hecho noche en una misma posada, habitación y cama en una posada del lugar de Restábal, viniendo juntos a Motril. Esto mismo lo refirieron otros testigos igualmente. Algunos dudaban si se trataba de una mujer con ese parentesco o no, pero que era cierto que "dormían juntos en una cama” y que eso había traído al regidor "muchos disgustos con su mujer, de zelos," y que por tal motivo le daba voces y riñas muchas veces. Otro efecto era que muchos maridos no querían acudir "al doctor Isidro" cuando se encontraban enfermos o sus esposas, o alguien de su familia, "porque no les enamore las mujeres" ${ }^{10}$.

Estas percepciones sobre la vida y comportamientos de Isidro Pérez permitían alimentar las pruebas en favor de la querella que había introducido el licenciado Ojeda en los juzgados granadinos. Se cuestionaba la veracidad de que este hombre, supuesto médico, tuviera los títulos precisos para practicar la medicina. Además, había pruebas de que no había entregado los mismos cuando le fueron solicitados por la villa de Motril. En realidad, lo hizo muy posteriormente a que se le pidieran y, finalmente, cuando presentó los documentos requeridos, éstos, a juicio de sus opositores en la causa penal, no ofrecían totales garantías sobre su autenticidad a las personas que los habían visto, aunque posteriormente fueron acreditados al ser examinados judicialmente.

Los testigos de la acusación contra Pérez Merino insistían en confirmar los comportamientos lascivos y el trato deshonesto del regidor con mujeres casadas, estando ausentes sus maridos. También, reiteraban sus condenas hacia los comportamientos amorales del regidor porque, según decía Ojeda, "se levanta de la cama de su mujer y se ua a acostar a la de la prima, de lo qual la mujer se quexa y clama pidiendo justicia al çielo”.

9 AGS, CC, leg. 1810, doc. 3, f. 5. 
Incluso se insistía en que el regidor había tenido un primer matrimonio en la almeriense villa de Purchena, pero que la había envenenado por estar amancebado con una prima suya, y que, luego de la muerte de su esposa, se trasladó a vivir con su amante a la villa de Baeza. Posteriormente, una vez en Cazorla, se decía que "solicitaba a la mujer de un Bartolomé Martínez y [que] por casarse con ella, estando el susodicho enfermo, en una granada, le dio veneno; y lo hizo por casarse con la dicha su mujer, de que ubo notiçia por la justicia [sobre que] se le hizo causa". De la condena se libró del modo ya indicado anteriormente, con el apoyo y ayuda de un hermano suyo que era fraile franciscano. ${ }^{11}$

A pesar de estas informaciones referidas a experiencias vitales del regidor de Motril en las jienenses villas de Baeza y Cazorla, el acusado logró que la justicia de Jaén confirmara que la causa que allí se había seguido contra una mujer por escándalo no era contra aquella que él tenía en su casa como prima hermana María Merino, sino contra la hermana de ésta, una mujer llamada Doña Luisa Merino, con la que él no tenía aparentemente nada qué ver. ${ }^{12}$

Las percepciones sociales que evidencian las informaciones anteriormente analizadas permiten caracterizar la imagen del mal gobernante urbano, un edil municipal corrupto, con rasgos que no sólo refieren abusos de poder sino, sobre todo, a fragilidades sexuales del edil en términos que son conocidos, con mayor o menor énfasis, para espacios y contextos históricos diferentes en los territorios europeos y americanos de la Monarquía Hispánica (Mantecón, 2002A: 69-98; Barriera, 2003: 69-95 y 2010: 57-84; Undurraga Schuler, 2010: 35-71; Argouse, 2016: 219-252; Caselli, 2016: 161-196; Herzog, 2016: 59-78).

No obstante, el expediente judicial contra el doctor Isidro Pérez Merino añade otros componentes que permiten, desde su análisis, evaluar el peso de otros factores para desencadenar la intolerancia social hacia los comportamientos considerados excesivos, además de delictivos, en la España del siglo XVII: el homicidio. El desprecio hacia la vida humana se hacía especialmente grave y se presentaba como impresentable en una persona que supuestamente se aplicaba a la práctica de la medicina.

En este plano interviene muy especialmente el protagonismo atribuido por los testimonios e informaciones judiciales hacia la carga emocional que explica el itinerario vital, geográfico y social del regidor cuestionado.

11 AGS, CC, leg. 1810 , doc. 3 , f. $13 v^{0}-15 v^{\circ}$. 
Al mismo tiempo, el expediente judicial también hace posible comprobar la facilidad con que la gente común que vivía en estas sociedades preindustriales podía construirse identidades personales que podían llevar aparejados incluso procesos de empoderamiento social, como demuestra el ejemplo del lascivo regidor de Motril protagonista de estas páginas. En este caso, se describe un proceso exitoso hasta el acceso al regimiento de la villa granadina y el uso del poder que esto significaba en el espacio local de gran dinamismo que no dejó de recibir población a lo largo del siglo XVII.

A pesar de todo, los procesos podían ser inversos al trazado por el doctor Pérez Merino, quien, según describían sus demandantes evidenciaba una personalidad capaz de someter todo a todos sus caprichos, si era necesario incluso disponiendo de vidas y muertes a través del fraude y el artificio, el engaño y la picardía. Estos rasgos, quizá intensificados en las narrativas de los testigos de la acusación por el hecho de ser el regidor Isidro Pérez un forastero en Motril y antes de serlo allí lo había sido en otras villas y entornos andaluces. Los prejuicios negativos contra el forastero adquirían un valor propio como argumento a la hora de tratar de excluir a un adversario político en el plano local, añadiéndose los tribunales a los frentes de disputa por el poder en estos escenarios de la Monarquía.

\section{La acción de la justicia}

La justicia, por todo lo anteriormente explicado, jugaba un papel central para restaurar el orden y la paz pública en los espacios locales, que eran escenarios de tensiones a veces muy intensas, pero también para arbitrar en las luchas entre personas y facciones sociales por el uso del poder e, incluso, para constreñir o amplificar las oportunidades de los individuos para construirse una identidad personal en nuevos escenarios de recepción y favorecer, por lo tanto, la mejor o peor integración social. Las personas, las familias, parentelas, clientelas y facciones sociales participaban de forma muy diversa de conocimientos sobre estos referentes y circunstancias que articulaban la vida cotidiana y las estructuras de poder local en los territorios de la Monarquía Hispánica. ${ }^{13}$

El licenciado Ojeda, querellante en la causa contra el regidor Pérez Merino lo explicaba en su propia demanda al dirigirse a la justicia de la chancillería

13 Los estudios de Lorena Álvarez Delgado (2013: 471-497) y Pilar López Berajano (2016: 79-102) sobre Asturias en el siglo XVI y la Nueva Granada al final del periodo colonial ofrecen ejemplos contrastados de este tipo de prácticas y usos de la justicia en España y América. 
de Granada afirmando hacerlo para suplicar "que delitos tan graves no queden sin castigo [una vez que sea] abida información que ofrezco en esta corte [de justicia] de cómo el susodicho es rexidor y de cómo a cometido los dichos delitos, ante el escribano de cámara”.

Solicitaba que desde la justicia se dispusiera el prendimiento del regidor "y que un recetor de la corte, a su costa, baya y haga la sumaria de todos estos delitos y excesos, y conpulse todos los pleitos criminales que en razón de los susodicho ubieren fecho y, especialmente, se de a mi parte provisión para que la justicia de $\mathrm{Ba}[\mathrm{e}] \mathrm{za}$ conpulse los autos que se hizieron por aver muerto a su mujer", según indicaba, con la colaboración del boticario Cristóbal de Mirez. Sobre todo esto, decía que se podía contar con la información obtenida en su momento por las justicias de Jaén. Para seguirse la causa, Ojeda pedía la prisión de Isidro Pérez, su traslado a las cárceles de Granada, y el embargo de sus bienes, así como que se hiciera todo "a buen recaudo, a su costa, que por eso protesto acusa[r] de más en forma, y juro en forma esta querella”. ${ }^{14}$

A principios de mayo de 1635, cuando el regidor de Motril suplicó la intervención de la Cámara de Castilla para tramitar su solicitud de gracia regia se pidió desde la Cámara que se diera parte al licenciado Diego de Morales, para que dispensara de la información precisa de todo el caso en la Corte, y que fuera remitida allí toda la documentación contenida en los autos seguidos en la Chancillería de Granada, como "caso de Corte".

El 13 de mayo, después de que esto ocurriera, Isidro Pérez Merino presentó sus títulos "de aprobación y licencia dada para usar y ejerçer la facultad de medicina, escrito en pergamino, firmado de do[c]tor don Antonio Ponze de Santa Cruz y el do[c]tor Gallego Benitez de la serna y del do[c]tor Alonso Núñez”. El documento había sido fechado en Madrid el 27 de marzo de 1635, "signado y firmado de Pedro de Salas, escribano de Su Majestad". También presentó otro título, el de "de bachiller, escrito en latín, despachado por la universidad de Valencia”. ${ }^{15}$

Los títulos presentados por Isidro fueron examinados, aceptados y aprobados por peritos judiciales. El problema real de cuanto ocurría en Motril y en los juzgados de Granada con el doctor Isidro Pérez no era debido al ejercicio de sus prácticas médicas, al menos en los últimos tiempos en Motril, lo que no quiere decir que su impericia y poca preparación pudiera haber dejado atrás algunos cadáveres como fruto de su audacia con tratamientos

14 AGS, CC, leg. 1810, doc. 3, f. 3. 
absolutamente ineficaces. Eso no asocia su caso al más extendido de falsos expertos en remedios curativos nada empáticos con sus pacientes que hicieron de la estafa sobre su profesión un medio de vida, tanto en los entornos hispánicos como en otras sociedades del Antiguo Régimen.

Algunos eran tan audaces como el británico Robert Salmon, que a la altura de la primavera de 1836 aún se ganaba la vida vendiendo tratamientos no sólo ineficaces, sino también inusualmente dañinos para la salud, alcanzando una condena judicial por homicidio involuntario debido a los efectos nocivos de sus prácticas en la venta de tratamientos purgantes que acabaron la vida de uno de los pacientes de los remedios contra el reumatismo que él vendía, aunque no fabricara (O’Danachair, 2009: 200).

Estas situaciones no sólo eran conocidas en la vida cotidiana, sino que dejaron un testimonio con personalidad propia en la literatura barroca (Brioso Sánchez \& Brioso Santos, 2008: 39-55). Ese no debía ser el caso del doctor Isidro, aunque el arquetipo fuera utilizado por sus oponentes para articular la oposición y querella contra el regidor advenedizo. El delito de este hombre era, más que de estafa, como en los casos que alimentaban el imaginario y hacían más fácil la acusación, de negligencia dolosa o, al menos, de audacia, por dispensar tratamientos ineficaces o perjudiciales, quien sabe si consciente de ello o no. En la época eso también era punible. La sentencia adversa demuestra que la justicia encontró alguna prueba de la culpa en las acciones del médico que tan funestos resultados habían tenido para algunos de sus pacientes.

No obstante, también debe considerarse que en los contextos en que se desenvolvía este regidor andaluz los remedios curativos, cuando se trataba del modo en que afectaban a la gente común, todavía podían ubicarse en un abanico muy amplio que iba desde la medicina académica y erudita, fundada en impulsos de avance científico, hasta la curación casuística, empírica y basada en saberes tradicionales y que, incluso, a pesar de la vigencia de disposiciones restrictivas, podía llegar a facultarse para que ejercieran la medicina personas sin título y que eran peritos locales, depositarios de saberes más o menos eficaces para dolencias cotidianas en espacios o ámbitos donde no podía llegar a dotarse de oficiales más profesionalizados.

Un ejemplo contrastado entre estos extremos en lugares bien distantes de los amplios territorios de la Monarquía Hispánica lo ofrecen el boticario y agricultor toledano Bernabé García Bermúdez Cabeza de Vaca y, a miles de kilómetros de distancia y en una cronología más avanzada de la época colonial española, el franciscano fray Pedro Luis Pacheco en la Córdoba argentina de finales del Antiguo Régimen. 
Tras largas controversias con las autoridades coloniales, el padre Pacheco logró, tanto de éstas como de la Santa Sede, una licencia para poder atender a los enfermos en la capital cordobesa en julio de 1798 después de que se le hubiera separado de esa labor por no contar con titulación a propósito y ante la presión ejercida también por la propia sociedad cordobesa, puesto que justo un año antes de la decisión que le habilitaba de nuevo para atender a sus pacientes varios enfermos ya se habían dirigido al virrey para obtener una licencia para que el padre Pacheco pudiera ejercer la "caridad con sus fieles" atendiendo a los enfermos con su saber empírico de la medicina ${ }^{16}$. Además de empirismo, el padre Pacheco también contaba con la lectura académica como fuente de conocimiento para resolver los casos que le llegaban en la capital argentina.

El ejemplo del padre Pacheco no era extraordinario en el marco de las sociedades hispánicas durante el Antiguo Régimen. El Directorio de enfermeros y artífice de obras de caridad para curar las enfermedades del cuerpo de Simón López elaborado a mediados del siglo XVII y publicado con licencia de dos catedráticos de la universidad de Valladolid y uno de anatomía en la de Salamanca en 1668, con una primera versión en 1651, ofrece un magnífico ejemplo de remedios empíricos con vocación práctica y supervisión técnica (López, 2017). Obras como ésta auxiliaban ordinariamente a quienes se aplicaban cotidianamente en la práctica médica.

El ya mencionado boticario manchego Bernabé García, por su parte, por ejemplo, llegó a contar con una biblioteca de un centenar de volúmenes debido a su interés por conocer remedios para sanar, labor a la que se aplicó a principios del siglo XVIII. Compartía con el doctor Isidro, además, sus empeños en la gestión municipal, en este caso castellana, aunque, a diferencia de Isidro Pérez, Bernabé García se empeñó en las labores de gobierno después de dejar su botica en 1710, casi dos décadas más tarde de haber iniciado la asistencia de fármacos para sus vecinos, quizá también influido por los saberes transmitidos por su padre, el cirujano Eusebio García que ejerció como tal en su localidad manchega en la segunda mitad del siglo XVII hasta su muerte en 1688, o aprendidos con su suegro o con su cuñado, también aplicados en las labores de botica y todos coetáneos del protagonista de estas páginas (Martín Verdejo, 2004: 113-166).

En el caso de este boticario manchego, al contrario que lo que experimentó el doctor Isidro Pérez en Motril, su ayuntamiento siempre confió en él para negociar y lograr rebajas de impuestos reales, justificar los arbitrios 
acordados por la villa de Domingo Pérez o evitar cargos y velar por los intereses de sus vecinos en pleitos y juicios con otras instancias.

Anteriormente ya se analizó la cuestión de los autos criminales seguidos por la justicia de Jaén sobre la muerte de la primera esposa de Isidro Pérez Merino, que cesaron sin responsabilizar al marido de este desenlace tan funesto. Por otro lado, los títulos académicos del doctor Isidro, como parece haber reconocido la justicia, debieron haberle llegado después de haber dedicado ya tiempo aplicándose a la práctica de la medicina. Pudieron, por lo tanto, ser un factor que fragilizaba la posición del regidor de Motril para enfrentarse a sus adversos en la estructura de poder local, pero ese argumento quedó desactivado en el momento que el peritaje judicial reconoció los títulos presentados por el edil.

Aún queda por aclarar la posible responsabilidad de Pérez Merino en las defunciones causadas por tratamientos curativos erróneos, además de su supuesta inclinación para practicar chantajes sexuales con mujeres de los entornos en que se movía y, finalmente, evaluar las malas prácticas y corruptelas en que hubiera participado.

Las dificultades que llevó aparejado su indulto, puesto que acabó precisando una importante tasación de compensaciones, dan una prueba fehaciente de que estas materias eran muy relevantes, y que los opositores contra el regidor de origen foráneo en Motril habían dado con un flanco débil en la posición social de este edil: alguna responsabilidad tenía el médico en el fallecimiento de alguno de sus pacientes. La sentencia condenatoria en la chancillería de Granada así lo venía a demostrar.

A pesar de todo, la obtención del indulto también limitaba mucho esas responsabilidades penales, puesto que la gracia del rey se aplicaba para evitar la aspereza de la sentencia y sus efectos más extremos. Este desenlace da cuenta de la propia fortaleza y empoderamiento de Isidro Pérez hasta ese momento en la villa granadina, al menos de forma suficiente como para lograr apoyos y recursos bastantes para costear el pleito criminal y argumentar en su favor tanto durante el mismo como en el transcurso del suplicatorio de indulto hasta lograr la conmutación de la condena dada por la chancillería de Granada.

\section{Conclusiones}

La documentación consultada informa sobre la materia del conflicto, permite constatar la presencia de certidumbres y también de fantasías 
contenidas en los expedientes judiciales, así como conocer la forma de evaluación judicial y estima de las condiciones para hacer cristalizar la acción de la justicia y sus últimas expresiones. En aplicación de la justicia, considerando todas estas facetas, el doctor Isidro pudo proseguir su actividad médica, así como gozar de una posición de poder y autoridad en su escenario vital. Seguramente, no obstante, después del proceso seguido en la chancillería de Granada y de la necesidad de emplearse a fondo para lograr la gracia del rey, Isidro Pérez Merino debió ser mucho más cauto y prudente a la hora de conducirse con sus vecinos.

De lo que no informa la documentación consultada es sobre la reconstrucción del mapa de poder en esos escenarios locales, para comprobar si las posiciones del supuestamente lascivo regidor le permitieron luego del indulto proseguir sucumbiendo a sus fragilidades sexuales, o si logró recomponer en Motril la misma posición y posibilidades de poder que había tenido antes de este encuentro judicial con sus adversarios y con el arbitraje de la Corona.

Isidro Pérez ofrecía un cuadro particular en el Motril de la segunda mitad del siglo XVII, era foráneo, se había ubicado en una posición de poder local que había sido capaz de construirse por sí mismo, hasta alcanzar el regimiento municipal, además de gozar de una herramienta de dominación en ese mismo escenario ligada a la práctica curativa, que utilizaba también ilícitamente para dar satisfacción a sus caprichos vitales y que, en el momento de verse inmerso en la querella judicial promovida por sus adversos en la villa granadina, trataba de reforzar con su proyecto de ubicación en el mismo escenario a un boticario de su confianza personal.

Quizá era eso lo que trataban de frenar los rivales del médico de cara a afectar decisivamente la labor de gobierno municipal: el proceso de empoderamiento del edil forastero, precisamente en momentos en que la propia vida y actividad urbana se mostraba dependiente del aporte que suponían residentes y avecindados procedentes de otros lugares de Andalucía y del interior peninsular. Las limitaciones que encontraba en el proceso de integración social de este hombre en la comunidad urbana de Motril también quedaban transparentadas en la información que contenía el expediente judicial formado en Granada y trasladado a la Corte para su determinación definitiva.

Las declaraciones de los testigos posibilitan conocer la intolerancia social hacia ciertos comportamientos considerados abusivos por parte del regidor Pérez Merino que ellos, y no sólo la facción adversa al médico en el gobierno municipal, consideraban inadmisibles. Los juzgados también 
integraban estos argumentos y los sopesaban a la hora de decidir sobre la intensidad y la forma de reparación exigible al inculpado, así como sobre las condiciones para renovar su reintegro a la vida social en el entorno en que había cometido sus excesos y delitos, ofreciendo una imagen muy veraz de la vigencia de una justicia negociada y arbitral que impregnaba cada ámbito de intervención de las instituciones, desde el escenario local hasta la Cámara y Consejo de Castilla.

La ciudad no era un escenario pasivo en estos procesos de recomposición del orden y paz pública, puesto que intervenía a través de sus agentes, ciudadanos, testigos y gobernantes, afectando también a las decisiones adoptadas por la Corona en esta última instancia de justicia que consistía en la decisión sobre las posibilidades de conmutación de condenas dadas. Además, en este caso, la intervención de las partes y sus ciudadanos afines o contrarios en los tribunales de justicia andaluces, así como del rey a través del ejercicio de la gracia, dispensaron una oportunidad de recomposición negociada de la paz pública que permitía también una reinserción del reo a sus funciones en la propia comunidad urbana de Motril. 


\section{Q Bibliografía}

»Álvarez Delgado, L. (2013). Juegos de estrategia en los tribunales. Planteamientos tácticos entre partes litigantes a través de un proceso inquisitorial complejo del siglo XVI. Clío \& Crimen: Revista del Centro de Historia del Crimen de Durango, 10, 471-497.

»Argouse, A. (2016). Otorgo que doy mi poder cumplido: Apoderamiento y representación voluntaria en la administración de justicia virreinal (Santiago de Chile, 1647-1725). En E. Caselli (Coord.), Justicias, agentes y jurisdicciones: de la Monarquía Hispánica a los Estados Nacionales (España y América siglos XVI-XIX), Madrid-México, FCE, 219-252.

"Attreed, L. (1992). Arbitration and Growth of urban liberties in Late Medieval England. Journal of British Studies, 31, 3 (Jul.), 205-235.

»Barral, M.E. (2008). De mediadores componedores a intermediarios banderizos: el clero rural de Buenos Aires y la 'paz común' en las primeras décadas del siglo XIX. Anuario IEHS, 23, 151-174.

» Barriera, D.G. (2003). La ciudad y las varas: justicia, justicias y jurisdicciones (ss. XVI-XVIII). Revista de Historia del Derecho, 31, 69-95.

»Barriera, D.G. (2010). El execrable libro de sus hechos: cultura jurídica, retórica y deslegitimación de la autoridad en un proceso contra el alcalde del Rosario (1810-1811). Anuario del Instituto de Historia Argentina, 10, 5784.

»Breen, M. P. (2011). Law, Society, and the State in Early Modern France. The Journal of Modern History, 83, 2 (June), 346-386.

»Brioso Sánchez, M. \& Brioso Santos, H. (2008). El falso médico como figura literaria: de Meneandro a Molière, HABIS, 39, 39-55.

»Caselli, E. (2016). Vivir la justicia: los réditos del oficio de juzgar y su incidencia en las disputas jurisdiccionales (Castilla en la temprana Edad Moderna). En E. Caselli (Coord.), Justicias, agentes y jurisdicciones: de la Monarquía Hispánica a los Estados Nacionales (España y América siglos XVI-XIX), Madrid-México, FCE, 161-196.

» Fernández Albaladejo, P. (1992). La resistencia en las Cortes. En su obra Fragmentos de Monarquía, Madrid, Alianza, 331-332.

»Fortea Pérez, J. I. (2004). Las ciudades, sus oligarquías y el gobierno del Reino. En Feros, A. \& Gelabert, J. (dirs.), España en tiempos del Quijote, Barcelona. Ed. Punto de Lectura, 235-278.

»Gil Pujol, X. (2016). La fábrica de la Monarquía. Traza y conservación de la Monarquía de España de los Reyes Católicos y los Austrias, Madrid, Real Academia de la Historia, 2016.

»Ginsberg, M. (1965). On Justice in Society, Harmondsworth-Baltimore, Penguin.

" Herzog, T. (2016). En torno a las relaciones sociales: Nosotros y ellos. Un análisis a partir de los procesos incoados al presidente de la Audiencia de Quito a mediados del siglo XVIII. En E. Caselli (Coord.), Justicias, agentes y 
jurisdicciones: de la Monarquía Hispánica a los Estados Nacionales (España y América siglos XVI-XIX), Madrid-México, FCE, 59-78.

» Herreros Cleret de Langavant, B. \& Mantecón Movellán, T.A. (2013). Hacer la guerra al Diablo en mundos de Ultramar: las fronteras misioneras del Chaco y el Paraná en el siglo XVIII. Chronica Nova, 39, 158-161.

" Hufton, O. (1997 [1995]). The prospect before her. A history of women in Western Europe. Vol. 1. 1500-1800, Londres, Haper Collins.

» Kurki, L. (2000). Restorative and community justice in the United States. Crime and Justice, 27, 235-303.

»López, S. (2017 [1997]). Directorio de enfermeros. (Simón López 1651). Estudio, transcripción e índices a cargo de Antonio C. García Martínez y otros, Madrid, Consejo General de Enfermería en España.

"López Berajano, P. (2016). Empapelar al enemigo: el recurso a los procesos judiciales como estrategia de la acción política (Nueva Granada entre colonia y república): En E. Caselli (Coord.), Justicias, agentes y jurisdicciones: de la Monarquía Hispánica a los Estados Nacionales (España y América siglos XVI-XIX), Madrid-México, FCE, 79-102.

" Mantecón, T.A. (1990). Contrarreforma y religiosidad popular en Cantabria, Santander, Universidad de Cantabria-Asamblea Regional de Cantabria, 1990.

" Mantecón T.A. (1995). La capacidad del clero secular para apaciguar las disputas entre los campesinos montañeses del siglo XVIII. En E. Martínez Ruiz \& V. Suárez Grimón (Eds.), Iglesia y sociedad en el Antiguo Régimen. III Reunión Científica de la Asociación Española de Historia Moderna (1994), Las Palmas de Gran Canaria, Universidad de Las Palmas de Gran Canaria.

» Mantecón, T.A. (1998). La muerte de Antonia Isabel Sánchez. Tiranía y escándalo en una sociedad rural del Norte de España durante el Antiguo Régimen, Alcalá de Henares, Centro de Estudios Cervantinos.

»Mantecón, T.A. (2002). El peso de la infrajudicialidad en el control del crimen durante la Edad Moderna. Estudis: Revista de Historia Moderna, 28, 43-76.

" Mantecón, T.A. (2002A). El mal uso de la justicia en la Castilla del siglo XVII. En J.I. Fortea / J.E. Gelabert \& T.A. Mantecón (Coords.), Furor et rabies: violencia, conflicto y marginación en la Edad Moderna, Santander, Universidad de Cantabria, 69-98.

» Martín Verdejo, F. (2004). La vida y la biblioteca de Bernabé García, boticario rural del siglo XVIII. Asclepio, LVI-2, 113-166.

" Matikainen, O. / Lidman, S. (eds.) (2014). Morality, Crime and Social Control in Europe, 1500-1900, Helsinki, SKS.

"Nader, H. (1990). Liberty in Absolutist Spain: The Habsburg Sale of Towns 1516-1700, Baltimore, The Johns Hopkins University Press.

»O'Danachair, D. (ed.) (2009). The Newgate Calendar, vol. 6, Published by the Exclassics Project, 2009, p. 200 [http:www.exclassics.com (9/4/2017)].

»Powell, E. (1984). Settlement of disputes by arbitration in fifteenth-century England. Law and History Review, 2, 1, Spring, 21-43.

» Roodenburg, H. \& Spierenburg, P. (eds.) (2004). Social Control in Europe. 1. 
1500-1800, Columbus (OSUP).

»Sabean, D.W. (1993 [1984]). The conscience of the por: a village detective story (1733-43). En su libro Power in the blood. Popular culture \& village discourse in early modern Germany, Cambridge, CUP, 144-173.

»Truchuelo, S. (2013). Villas y aldeas en el Antiguo Régimen: conflicto y consenso en el marco local castellano. Mundo Agrario, 14, 27, Diciembre.

»Tuck, R. (1974). Power and authority in Seventieenth-Century England. The Historical Journal, 17, 1 (Mar.), 43-61.

» Undurraga Schuler, V. (2010). Valentones, alcaldes de barrio y paradigmas de civilidad. Conflictos y acomodaciones en Santiago de Chile, siglo XVIII. Revista de Historia Social y de las Mentalidades, 14, 2, 35-71. 